Editorial

\title{
Carbon Nanostructures for Energy and Sensing Applications
}

\author{
Kunal Mondal $\mathbb{D},{ }^{1}$ Bhuvaneshwari Balasubramaniam, ${ }^{2}$ Ankur Gupta $\left(\mathbb{D},{ }^{3}\right.$ \\ Abdellatif Ait Lahcen, ${ }^{4}$ and Mirosław Kwiatkowski ${ }^{5}{ }^{5}$ \\ ${ }^{1}$ Materials Science and Engineering Department, Idaho National Laboratory, Idaho Falls, ID 83415, USA \\ ${ }^{2}$ Department of Chemical Engineering, Indian Institute of Technology Kanpur, Kanpur, Uttar Pradesh, India \\ ${ }^{3}$ School of Mechanical Sciences, Indian Institute of Technology Bhubaneswar, Kansapada, Odisha, India \\ ${ }^{4}$ Hassan II University of Casablanca, Casablanca, Morocco \\ ${ }^{5}$ AGH University of Science and Technology, Kraków, Poland \\ Correspondence should be addressed to Kunal Mondal; kmondal.iitk@gmail.com
}

Received 25 March 2019; Accepted 26 March 2019; Published 22 May 2019

Copyright (c) 2019 Kunal Mondal et al. This is an open access article distributed under the Creative Commons Attribution License, which permits unrestricted use, distribution, and reproduction in any medium, provided the original work is properly cited.

The demand of energy storage as well as affordable and easy-to-handle healthcare and environmental monitoring systems is increasing with the incessant growth in the world population. Therefore, there is a prodigious need for more economic and efficient technologies for energy storage and sensors for healthcare and environmental monitoring application. The advancement of carbon nanostructured materials, dimensions ranging from tens to several hundreds of $\mathrm{nm}$, dating back to the past few years, has seen a tremendous scientific growth in the field of battery and supercapacitor [1], bio, chemical, and mechanical sensors [2-6], and possible related applications as illustrated in Figure 1 [7-15]. These nanostructured carbon materials own unique characteristics, such as superior electrical conductivity, tunable porosity, outstanding mechanical strength, and remarkable thermal, optical, and chemical properties because of their nanosized and very high surface-area-to-volume ratio $[16,17]$. These outstanding structural characteristics of carbon nanomaterials help them to interact with other materials for numerous innovative applications, such as in energy storage and conversion and sensing.

This special issue is envisioned to provide an insight into the role of nanoscopic features in improving the functional properties of carbon nanomaterials and their composites, such as amorphous and graphitic carbon, carbon nanofibers, nanotubes, and graphene, and composites with metal and metal oxides. In this special issue on carbon nanostructures for energy and sensing applications, we have invited a few papers that address such matters.

The first and second papers of this special issue address electro-oxidation of formic acid (FAO). The first paper reported about the $\mathrm{CuOx}-\mathrm{Pd}$ nanocatalyst supported on a glassy carbon (GC) electrode. A distinct class of nanostructured catalyst made up of binary palladium nanoparticles (PdNPs) and copper oxide nanowires ( $\mathrm{CuOxNWs)}$ has been realized onto the GC electrode. It was found that the deposition sequence of both nanostructures onto the carbon electrode influenced the catalytic efficiency heavily. The highest catalytic activity and stability were obtained at the GC electrode surface with partially deposited CuOxNWs on $\mathrm{CuOx} / \mathrm{Pd}$ catalysts. The second paper demonstrates a binary platinum $(\mathrm{Pt})$ nanocatalyst on glassy carbon surfaces with earth abundant iron oxide nanowires $(\mathrm{FeOx} / \mathrm{Pt})$ for improved formic acid electro-oxidation, and it was found that nanocatalyst displayed a better ( $\sim 4$ times) catalytic activity as compared to bare $\mathrm{Pt}$ electrode and that when triggering the catalyst at $\sim 0.5 \mathrm{~V}$, the catalysis enhanced $\sim 8$ times.

Carbon nanomaterials, specifically graphene, graphene oxide, nanotubes, and nanofibers owing to their high accessible surface area and porosity, capability of easy surface functionalization and suitability make them to serve as a support material for various types of adsorbents to solve the purpose of desulfurization [18]. The third paper is a comprehensive review on carbon nanomaterials towards 


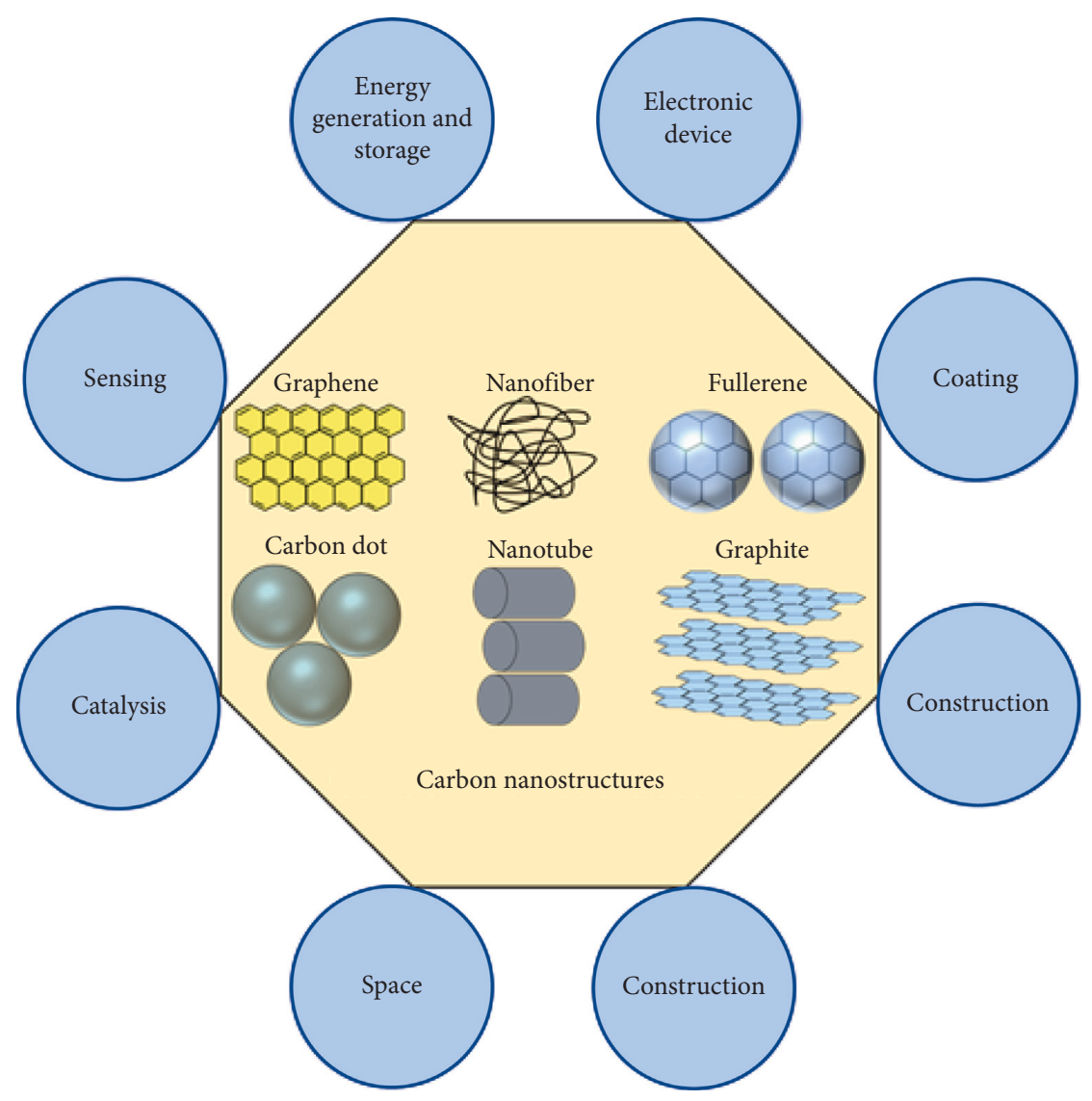

Figure 1: Applications of carbon nanostructures.

adsorptive desulfurization of fuels. The paper also describes the current trends in industrial desulfurization and its restrictions.

The fourth paper in this issue offers an original research on dye-sensitized solar cell (DSC) fabrication using carbon nanotube paints. The research confirms that it can generate power from absorbed photons on electrode surfaces and, however, was unable to obtain high fill factor (FF). It has also been explained that the possible reason could be the high leakage current in the device and high internal resistance involved during fabrication of the cells. The probable application of this type of paint-type DSCs will be in the electronic wallpaper, window glass, and furniture, wherever the carbon paint can be used.

The last paper is about the green synthesis of luminescent quantum dots of carbon from lemon juice using the one-pot simple hydrothermal method. The obtained quantum carbon dots (C-dots) were fully characterized using different complementary characterization techniques. The interesting discovery in this paper is that Cdots have strong green light emission with 14.86-24.89\% quantum yield range as a function of hydrothermal temperatures. These outcomes propose that the carbon dots could find potential applications in the field of optoelectronic and bioimaging.

This editorial encourages students, researchers, scientists, and engineers to conduct energetic multidisciplinary and collaborative research focused on applications and new insights into the carbon family and nanostructured carbon materials.

\section{Conflicts of Interest}

The editors declare no conflicts of interest.

\section{Acknowledgments}

The editors want to acknowledge all the referees who participated for reviewing articles for this special issue.

\section{Kunal Mondal \\ Bhuvaneshwari Balasubramaniam Ankur Gupta \\ Abdellatif Ait Lahcen \\ Mirosław Kwiatkowski}

\section{References}

[1] K. Mondal, R. Kumar, and A. Sharma, "Metal-oxide decorated multilayered three-dimensional (3D) porous carbon thin films for supercapacitor electrodes," Industrial \& Engineering Chemistry Research, vol. 55, no. 49, pp. 12569-12581, 2016.

[2] M. A. Ali, K. Mondal, Y. Jiao et al., "Microfluidic immunobiochip for detection of breast cancer biomarkers using hierarchical composite of porous graphene and titanium dioxide nanofibers," ACS Applied Materials \& Interfaces, vol. 8, no. 32, pp. 20570-20582, 2016. 
[3] M. A. Ali, C. Singh, K. Mondal, S. Srivastava, A. Sharma, and B. D. Malhotra, "Mesoporous few-layer graphene platform for affinity biosensing application," ACS Applied Materials \& Interfaces, vol. 8, no. 12, pp. 7646-7656, 2016.

[4] K. Mondal, M. A. Ali, S. Srivastava, B. D. Malhotra, and A. Sharma, "Electrospun functional micro/nanochannels embedded in porous carbon electrodes for microfluidic biosensing," Sensors and Actuators B: Chemical, vol. 229, pp. 82-91, 2016.

[5] M. A. Ali, K. Mondal, Y. Wang et al., "In situ integration of graphene foam-titanium nitride based bio-scaffolds and microfluidic structures for soil nutrient sensors," Lab on a Chip, vol. 17, no. 2, pp. 274-285, 2017.

[6] K. Mondal, M. A. Ali, C. Singh, G. Sumana, B. D. Malhotra, and A. Sharma, "Highly sensitive porous carbon and metal/ carbon conducting nanofiber based enzymatic biosensors for triglyceride detection," Sensors and Actuators B: Chemical, vol. 246, pp. 202-214, 2017.

[7] K. Mondal, S. Bhattacharyya, and A. Sharma, "Photocatalytic degradation of naphthalene by electrospun mesoporous carbon-doped anatase $\mathrm{TiO}_{2}$ nanofiber mats," Industrial \& Engineering Chemistry Research, vol. 53, no. 49, pp. 1890018909, 2014.

[8] K. Mondal, J. Kumar, and A. Sharma, "Self-organized macroporous thin carbon films for supported metal catalysis," Colloids and Surfaces A: Physicochemical and Engineering Aspects, vol. 427, pp. 83-94, 2013.

[9] S. Katiyar, K. Mondal, and A. Sharma, "One-step sol-gel synthesis of hierarchically porous, flow-through carbon/ silica monoliths," RSC Advances, vol. 6, no. 15, pp. 1229812310, 2016.

[10] K. Mondal, J. Kumar, and A. Sharma, " $\mathrm{TiO}_{2}$-nanoparticlesimpregnated photocatalytic macroporous carbon films by spin coating," Nanomaterials and Energy, vol. 2, no. 3, pp. 121-133, 2013.

[11] A. K. Srivastava, K. Mondal, K. Mukhopadhyay, N. E. Prasad, and A. Sharma, "Facile reduction of para-nitrophenols: catalytic efficiency of silver nanoferns in batch and continuous flow reactors," RSC Advances, vol. 6, no. 115, pp. 113981-113990, 2016.

[12] B. Balasubramaniam, K. Mondal, K. Ramasamy, G. S. Palani, and N. R. Iyer, "Hydration phenomena of functionalized carbon nanotubes (CNT)/cement composites," Fibers, vol. 5, no. 4, p. 39, 2017.

[13] J. B. Andrews, K. Mondal, T. V. Neumann et al., "Patterned liquid metal contacts for printed carbon nanotube transistors," ACS Nano, vol. 12, no. 6, pp. 5482-5488, 2018.

[14] S. Singh, K. Mondal, and A. Sharma, " $\mathrm{ZnO}$ nanoparticle fortified highly permeable carbon/silica monoliths as a flowthrough media," Langmuir, vol. 33, no. 31, pp. 7692-7700, 2017.

[15] N. Ben Messaoud, A. Ait Lahcen, C. Dridi, and A. Amine, "Ultrasound assisted magnetic imprinted polymer combined sensor based on carbon black and gold nanoparticles for selective and sensitive electrochemical detection of bisphenol A," Sensors and Actuators B: Chemical, vol. 276, pp. 304-312, 2018.

[16] K. Mondal and A. Gupta, "Recent advances in carbonsemiconductor nanocomposites for water remediation," in Water Remediation, S. Bhattacharya, A. B. Gupta, A. Gupta, and A. Pandey, Eds., pp. 45-74, Springer, Singapore, 2018.

[17] M. Kwiatkowski, A. Policicchio, M. Seredych, and T. J. Bandosz, "Evaluation of $\mathrm{CO}_{2}$ interactions with S-doped nanoporous carbon and its composites with a reduced GO: effect of surface features on an apparent physical adsorption mechanism," Carbon, vol. 98, pp. 250-258, 2016.

[18] X.-L. Liu, J.-X. Guo, Y.-H. Chu et al., "Desulfurization performance of iron supported on activated carbon," Fuel, vol. 123, pp. 93-100, 2014. 


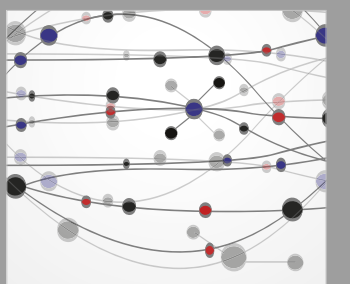

The Scientific World Journal
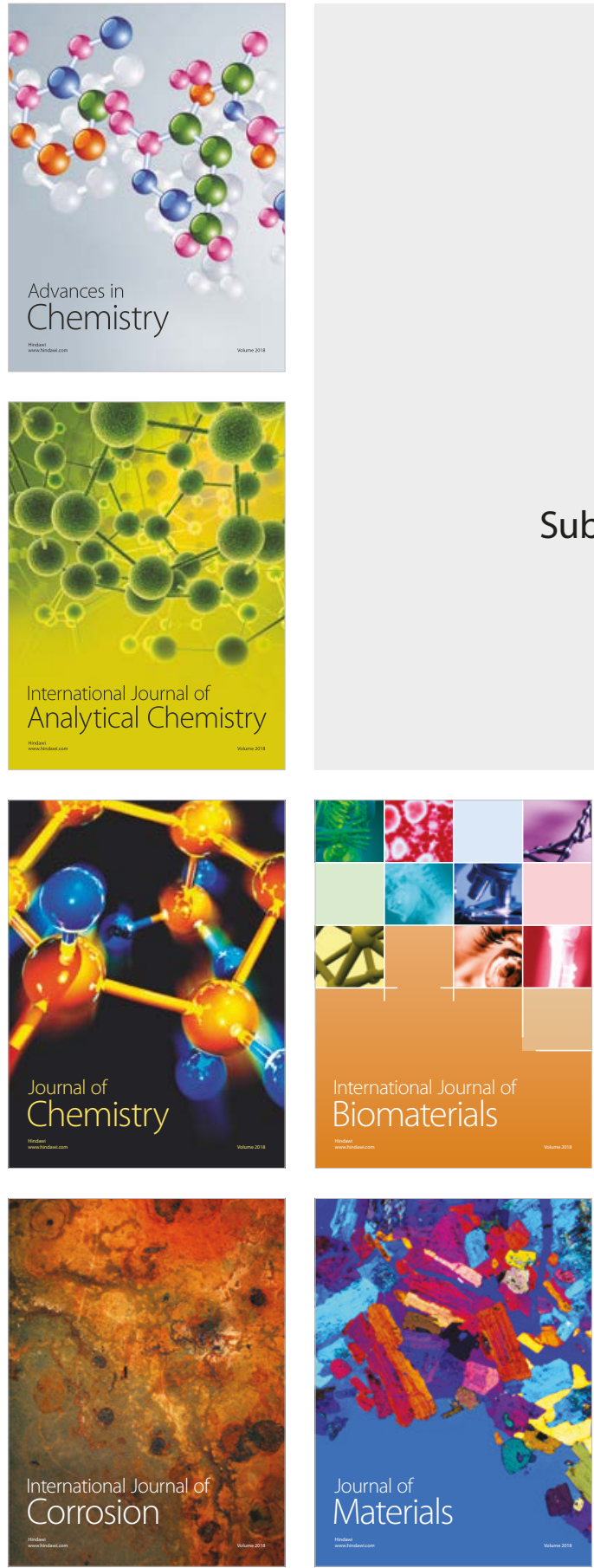

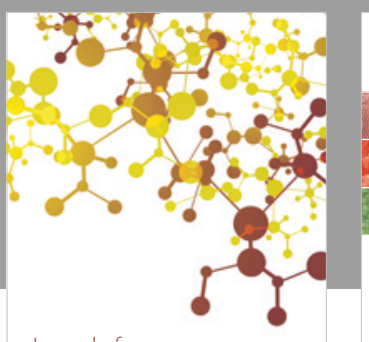

Journal of

Applied Chemistry
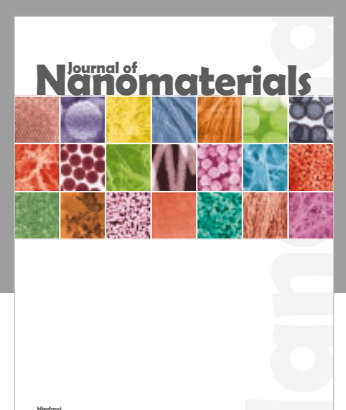

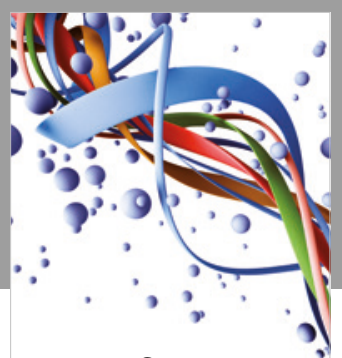

Scientifica

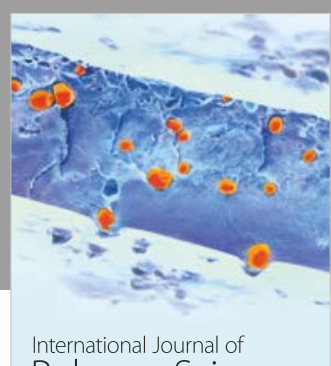

Polymer Science

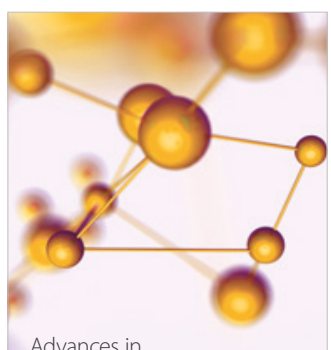

Physical Chemistry
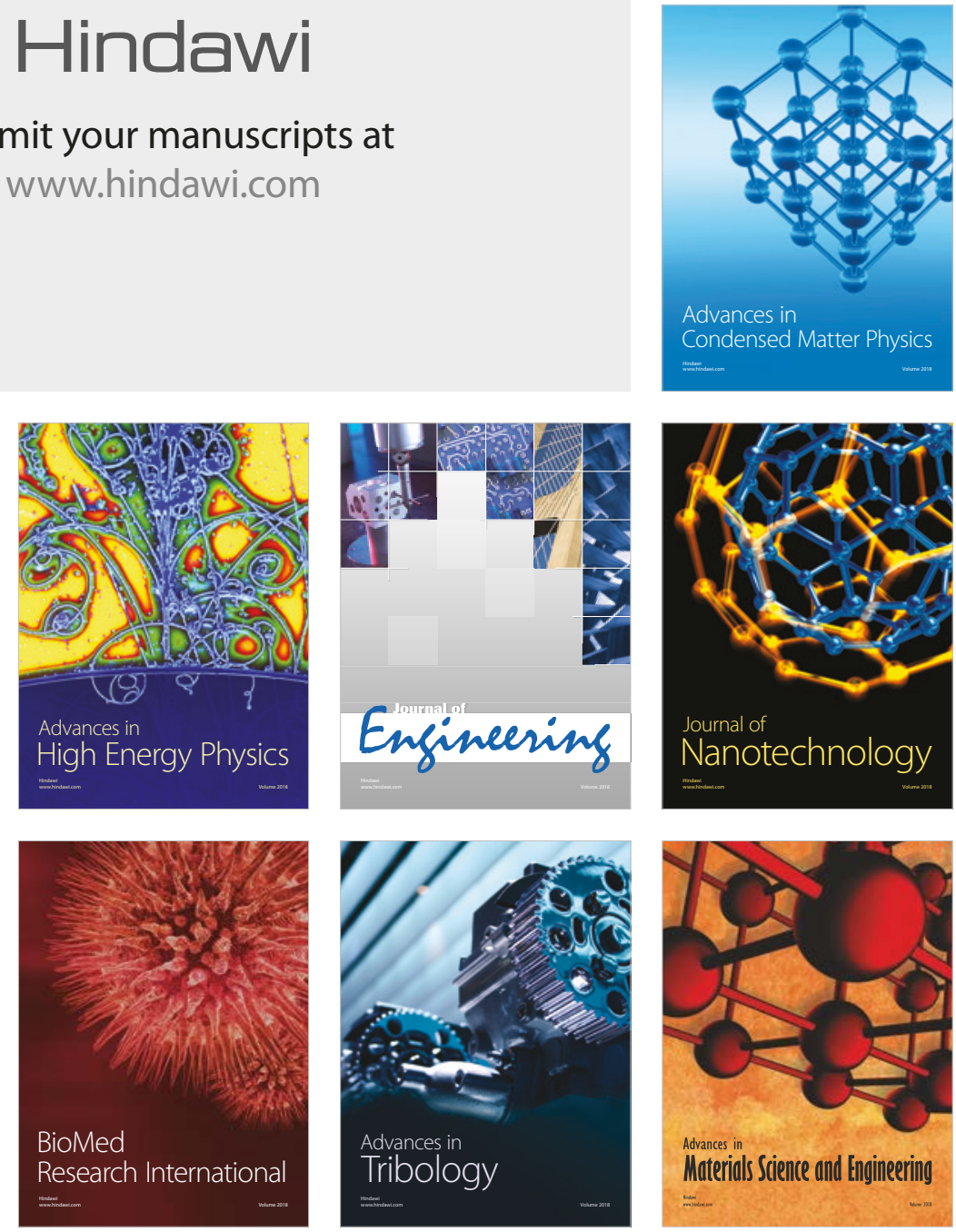